\title{
Workmanship standards and their application on ESA projects
}

\author{
Barrie D. Dunn \\ ESA-ESTEC, Noordwijk, The Netherlands
}

\begin{abstract}
Purpose - This paper aims to describe some of the European Space Agency (ESA) workmanship standards which are based on industrial practices. Coordination with National Aeronautics and Space Administration (NASA) Centres on workmanship issues is also to be described.

Design/methodology/approach - The first ESA (then ESRO) workmanship standard was published in 1972. It applied to the hand soldering of electronic assemblies and became a contractual document, either replacing, or supplementing a vast number of company standards that had existed in European manufacturing companies. Since then some 40 standards related to Materials and Processes have been developed by ESA, the majority of which are to be found in the European Cooperation for Space Standardization (ECSS) series of European standards.

Findings - It is shown that, where appropriate, the standards are backed by a number of ESA-approved skills training schools which provide training courses that result in the certification of operators, inspectors and instructors.

Originality/value - The workmanship standards are periodically revised in order to take into account newly developed technologies, the results of failure analyses (lessons learnt), laboratory and field test results, as well as some particular requests from industry.
\end{abstract}

Keywords Solder, Surface mount technology, Training, Spacecraft, Quality

Paper type Technical paper

\section{Workmanship}

Workmanship can be defined as, "the skill with which something was made or done". It is the product of effort or endeavour and relates very much to the skills of the person involved. These might be a craftsman able to fashion jewellery from precious metals, or an operator on the shop floor assembling spacecraft hardware. Such skills are acquired by training, and it is the physical skills, such as the handling of a blow-torch or soldering iron, which may result in either excellent workmanship, or shoddy workmanship. Samuel Johnson in the book Boswell's Life published in 1766 mentions that, even in those days, people had the strange opinion that everything should be taught from lectures - he concluded that chemistry was best taught from lectures, but, concerning workmanship, the teaching of making shoes could only be done by practical training!

Spacecraft hardware is generally produced in small quantities and often has unique designs that do not lend themselves to automatic machine assembly. For this reason skills training is paramount if we are to ensure products having a suitably high quality.

Manufacturing procedures are written to enable hardware to be produced by skilled operators in a reproducible manner. These documents may be referred to as Workmanship Standards as they define the materials and the processing steps in adequate detail. In order to avoid subjective disposition, the terms "excellent" or "shoddy" workmanship

The current issue and full text archive of this journal is available at www.emeraldinsight.com/0954-0911.htm

Soldering \& Surface Mount Technology 20/4 (2008) 37-44

(C) Emerald Group Publishing Limited [ISSN 0954-0911] [DOI 10.1108/09540910810902697] are replaced by acceptable or rejectable workmanship and this is done by making reference to physical characteristics that can be measured, or to illustrations which help to define what might be accepted or rejected.

\section{The beginning}

The European Space Research Organisation (ESRO), was created in 1962, but it was not until 1968 that the first satellite was successfully launched (ESRO 2B, intended to study cosmic rays and solar X-rays). Companies in the ten ESRO member states designed and manufactured that satellite and then continued with the fabrication of hardware for further programmes such as COS-B, Meteosat and OTS. The Materials and Processes Division (then Section) was expanded in 1969 and took on roles that involved the formation of a dedicated Materials Laboratory and the initiation of Materials and Processes (M\&P) Specifications. That specification tree included standards for the selection of spacecraft materials and processes (QRM-01) and standards for processes such as soldering (QRM-08). The soldering standard (ESRO, 1972) was issued in 1972 and became a contractual document for all subsequent space projects. It replaced a myriad of company standards which had consisted of either scant, three-page "how-to-solder" instructions, to the very detailed US standards used by the military and the American space industry. QRM-08 was the first European non-company standard to cover the process of soldering, the required materials, such as solder alloy and flux, and the accept-reject workmanship criteria was based on NASA NHB

The author would like to thank his colleagues Dave Adams and Gianni Corocher for their patience in the archiving of workmanship photographs and for the use of their photomicrographs. Also, to Carole Villette, who has tirelessly assisted as a key person in the working groups assigned to each ECSS Workmanship Standard. 
5300-4 (NASA, n.d.). This standard was developed in conjunction with the British Association for Brazing and Soldering who met every third month of the year in a room rented from Euston Station in London. Similar process standards were prescribed for crimping, repair of PCB assemblies, and the other processes that had been identified as "critical".

In 1973, ESRO was transformed into the European Space Agency and the European Space Conference decided to manage the Ariane launcher programme and start work on Spacelab and MAROTS. Subsequent years saw the QRM standards being reformatted as ESA-PSS documents and, more recently, into the present ECSS series of European standards. The following Sections of this paper will mainly focus on the various processes of soldering as this is where workmanship issues are most often encountered.

\section{Influence of failure modes on standard requirements}

Some early spacecraft electronic assemblies made and environmentally tested were seen to fail prematurely. These circuits were investigated in the ESA Materials Laboratory. Since then, we have developed a large data base of failure reports. Many topics related to the failures were further researched by means of small studies and the results of such works have been very influential during the updating of the ESA standards. Some failure modes reoccur from time to time as new companies or individuals enter the space manufacturing industry. Five of the most common examples encountered are summarised below.

\subsection{Terminal pins machined from brass and solderplated}

Very poor solderability causes rejected solder joints. Zinc from the brass alloy diffused through the coating to form a thin zinc oxide layer which is impossible to wet, even with active solder fluxes (Dunn, 1978). The standard was updated to require the presence of a $3 \mu \mathrm{m}$ barrier layer, either nickel or copper, to prevent such zinc diffusion.

\subsection{Soldering to gold finishes}

Pasty and very brittle joints associated with the soldering of gold-plated flat pack leads and antenna dipoles (Dunn, 1978). Gold-tin intermetallics are notoriously brittle as shown in Figure 1. All tin-lead soldering to gold is forbidden unless indium-lead alloys are employed.

\subsection{Pure tin electroplating}

Tin whiskers were observed to be growing on circuit boards and on a tin-plated electronic housing (Figures 2 and 3). The whiskers had a diameter of $1-6 \mu \mathrm{m}$ and lengths exceeding $2 \mathrm{~mm}$. Some whiskers were found to carry currents of between 22 and $32 \mathrm{~mA}$ before burning out (Dunn, 1976, $1987,1988)$. Pure tin is forbidden, as specified in materials and components specifications (ECSS-Q-60, n.d.; ECSS-Q-70B, 2004; ECSS-Q-70-08B， 2008; ECSS-Q-70-71, n.d.; ECSS-23500, n.d.).

The failure of electronic systems due to whisker growths is expected to be more prevalent following the EU directive to restrict the use of lead $(\mathrm{Pb})$ in electronics (even though spacecraft are exempt).
Figure 1 This thick gold-plated Kovar pin was soldered with tin-lead. The resulting tin-gold intermetallic is very brittle and contains micro-cracks (and an electrically intermittent connection) following thermal cycling

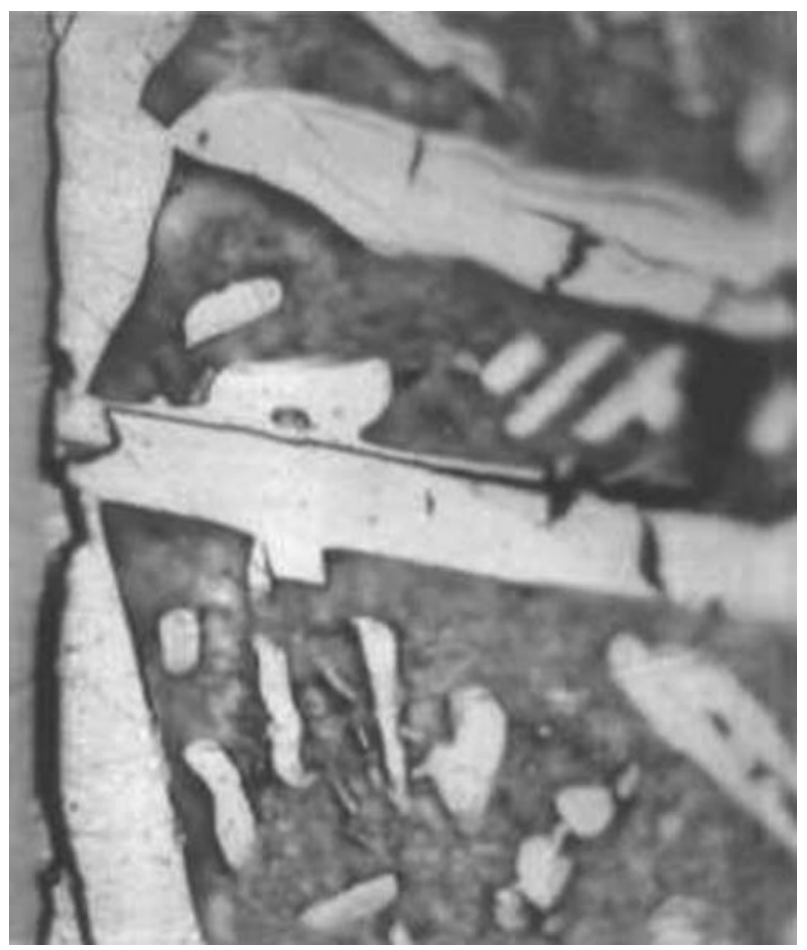

Figure 2 General view of tin whiskers on electroplated tin

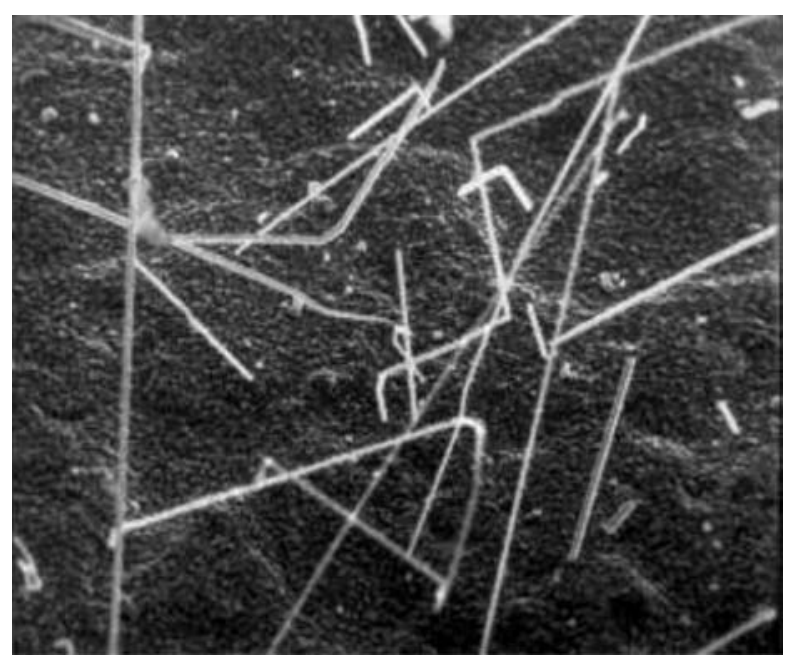

\subsection{Activated rosin solder flux}

Kovar leads on flat packaged component packages detached (broke off) due to stress corrosion resulting from the presence of activated flux residue combined with some residual stress in the lead during forming operations as shown in Figure 4 (Dunn and Chandler, 1980). It was found that fluxes purchased to the same trade name in different countries possessed totally different activations and $\mathrm{pH}$ values. Also, most mildly activated fluxes could initiate bimetallic and stress corrosion. The standards now limit activated flux to 
Figure 3 The tip of this $6 \mu \mathrm{m}$ diameter whisker supports surface of grain from which it grows - a growth mechanism is postulated in Dunn (1987)

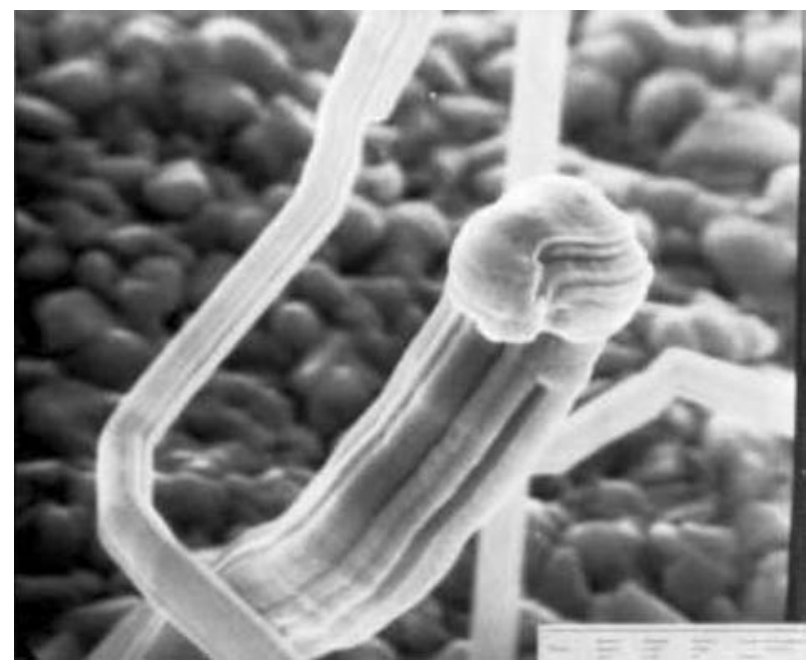

Figure 4 Detailed SEM micrograph of the surface of a cracked Kovar package lead: (a) the residual flux, together with residual stresses from lead-bending, has caused failure by stress corrosion; (b) shows the crack in microsection, it is a longitudinal section through the blistered gold plating (etched and incident light interference contrast picture)

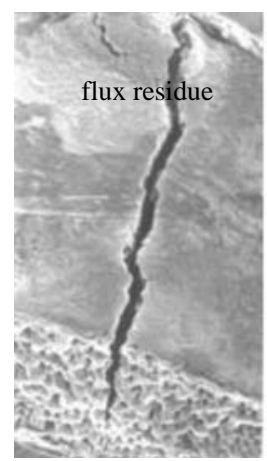

(a)

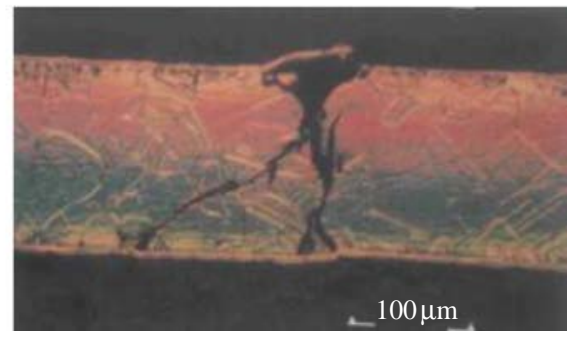

(b) pre-tinning; after which they must be removed. Only non-activated rosin is now permitted for assembly (ECSSQ-70-08B, 2008).

\subsection{Heat-shrinkable plastic sleeves containing solder performs}

Wires, stripped of their insulation can be lapjoined together using these devices. Heat from a hot air, or infra-red soldering gun causes the tube to shrink and the internal solder ring to melt so as to solder the wire strands together. The tube has two small plastic sealing rings at each end, which cause flux and its residues to become entrapped within the sleeve. Wire harnesses that supported several solder sleeves have been observed to cause outgassing (of the retained flux) under vacuum testing. Such contamination can cause corona effects in high voltage situations. Additionally, it is almost impossible to visually inspect such soldered connections. These devices are now forbidden and alternative methods for joining are prescribed (ECSS-Q-70-08B, 2008).

\section{Surface mount technology (SMT)}

The processes for soldering surface mount devices (SMDs) to circuit boards are not so well understood as those for leaded through hole components. Non-evaluated SMT processes have in the past produced connections having a poor workmanship and a low reliability. In order that specific "problem" areas could be resolved, ESA initiated several small studies over the past ten years. These are summarised in Table I.

Table I Recent studies related to SMT

\begin{tabular}{l} 
Study title (and reference) \\
\hline Evaluation of the effect of \\
ageing on the cleanability of \\
flux residues (Zou et al., 1999)
\end{tabular}

The effect of solder joint geometry on the mechanical fatigue of SMDs (Adile et al., 1999, in Italian; mechanical fatigue was performed at $20^{\circ} \mathrm{C}$ and $70^{\circ} \mathrm{C}$ )

\section{An investigation into ball grid array (BGA) Inspection Techniques (Dunn, 1987; employing various commercially available X-ray equipment)}

Assessment of electrically conductive adhesives (ECAs) for joining SMDs to PCB's (Thomas and Dunn, 1999)

Evaluation of thermally conductive adhesives as staking compounds during the assembly of spacecraft electronics (Tegehall and Dunn, 2001a; such adhesives are needed to dissipate heat from component packages)

Assessment of reliability of ball and column grid arrays (Tegehall and Dunn, 2001b; exposed to standard thermal cycling environments)

Impact of cracking beneath solder pads in PCB laminates on reliability of BGAs (Dunn and Tegehall, 2003)

\section{Main findings}

SMDs should be cleaned as soon as possible after soldering, but certainly within $24 \mathrm{~h}$. Cleaning efficiency increases to the fourth power as stand-off height increases

Large solder fillets are preferred. A stand-off height of $0.2 \mathrm{~mm}$ is better than either very small or very large stand-offs. Shorter joint lives were noted if test temperatures increased from $20^{\circ} \mathrm{C}$ to $70^{\circ} \mathrm{C}$. Longer life times observed when tested in vacuum instead of air

Some minor BGA defects not easily identifiable by all machines, major defects were inspectable. Illustrations used for workmanship standard

ECAs are not a drop-in replacement for solder paste. Electrical resistance is one order of magnitude greater than solder. Ablebond $8175 \mathrm{~A}$ gave best results

Commercial and space market surveyed, outgassing assessed, samples of compounds under ceramic quad flatpacks thermally cycled with good results, CV-2946 had considerably lower thermal conductivity than manufacturer's datasheet. Epotek-930 promising

Columns had best fatigue life, Thermount improved all fatigue lives, epoxy underfill created early failures. Dye-penetrant test method developed and workmanship illustrations generated

Low temperature extreme during thermal cycling is main cause of laminate cracking beneath solder pads to ceramic BGAs. Such cracks may improve fatigue life 
The ECSS standard for surface mount technology has been recently issued (ECSS-Q-70-38A, 2007). This is a major milestone as delays were inevitable as the results of our studies were awaited. Clearly, it is unacceptable to select SMD packages which cannot be reworked or removed from a populated spacecraft circuit board. Further testing was needed to evaluate methods for the repair of area grid arrays and other modern SMT packages (Schonbeck and Dunn, 2004; Tegehall and Dunn, 2005). It was also necessary to address the Standard's cleanliness test methods for printed circuit board assemblies that supported the latest varieties of SMT packages. The results of this latest investigation (Tegehall and Dunn, 2006) showed that if the PCBs were initially cleaned before assembly, and if pure, or mildly activated flux was employed during component mounting processes, then the ionic contamination level after assembly cleaning was well below the Standard's $1.56 \mu \mathrm{g} / \mathrm{cm}^{2}$. Further, the surface insulation resistance can be expected to be high. The new SMT standard contains many workmanship illustrations that include: partial reflow of solder paste, solder balls, X-radiographs of CGA and BGA mounted packages together with micrographs after the dye penetrant testing of BGAs. Some are shown in Figures 5-7.

\section{Approval of processes for ESA projects}

The majority of ESA space programmes require that each supplier to the project will appoint a materials and processes (M\&P) manager in accordance with ECSS-Q-70B (2004). This person will be the contact with ESA's M\&P Division. One important task will be for the supplier to follow the steps needed to gain approval for the materials, and later the manufacturing processes. These activities are prescribed in ECSS-Q-70B (2004). The following nomenclature is used by ESA and ECSS:

- materials are validated;

- mechanical parts are qualified;

- processes are verified; and

- operators and inspectors of critical processes are trained, certified and monitored.

Figure 5 Workmanship X-radiograph of assembled CGA showing a rejectable situation due to solder balls ( $>0.1 \mathrm{~mm}$ diameter) and bent columns (ECSS-Q-70-38A, 2007)

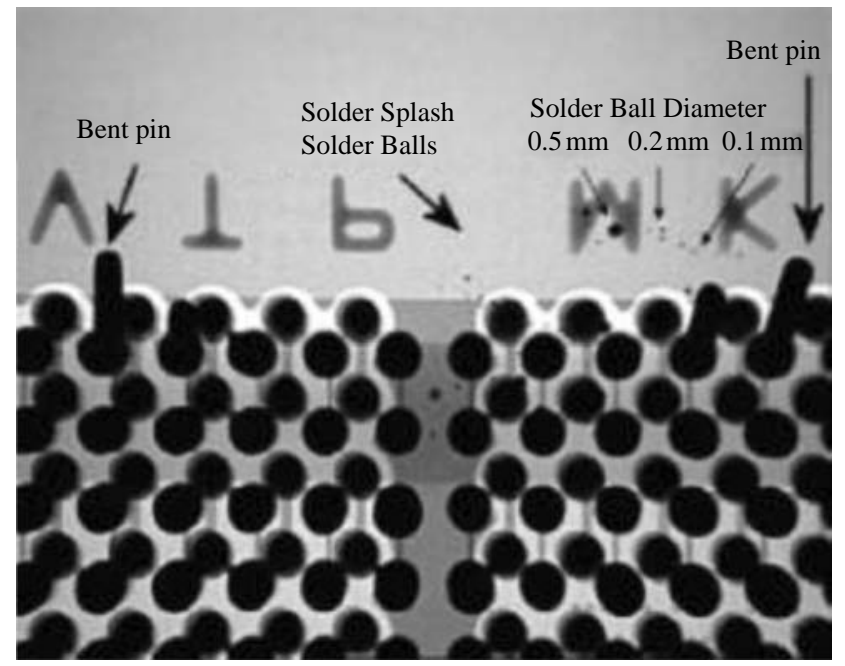

Figure 6 X-radiograph of assembled Column Grid Array showing more that 25 per cent voiding in solder fillets - reject according to workmanship requirements of ECSS-Q-70-38A (2007)

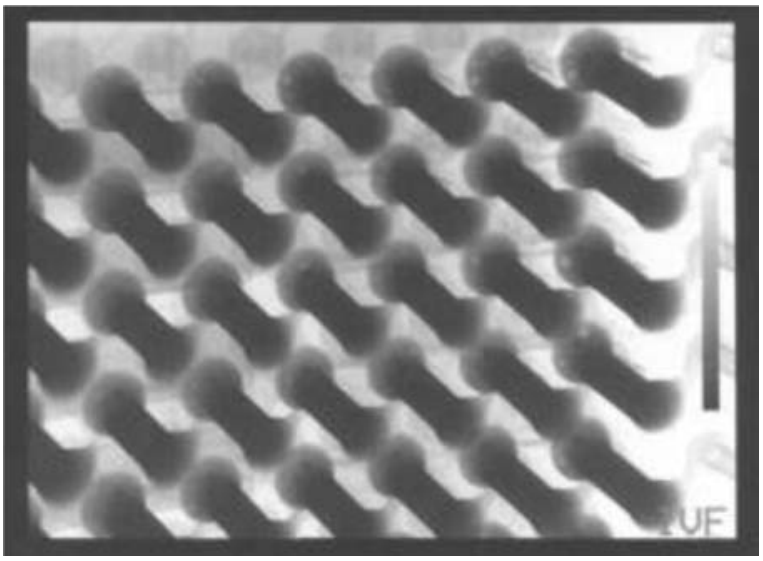

Figure 7 Asymmetry of solder fillets at $P C B$ is consequence of teardrop pads (acceptable), CGA columns have $<5^{\circ} \mathrm{C}$ tilt (acceptable)

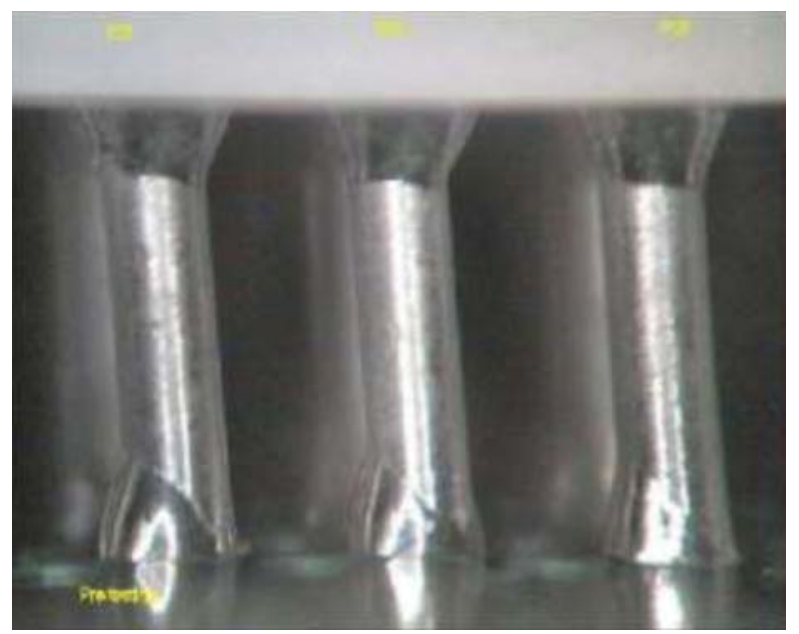

Critical processes such as those related to soldering are controlled on each ESA project by means of the project's declared processes list. Conventional hand soldering of leaded components using plated through hole technology (according to the design and processing techniques described in the Manual Soldering standard ECSS-Q-70-08B (2008)) will only require that the operator is trained and certified, and this will be explained in a future Section. The reworking of solder joints is permitted, but it can reduce the reliability of multilayer boards if repeated heat is applied to the joints. ECSS-Q-70-08B (2008) was relaxed in the way voids, or blow-holes, are assessed. Some thick multilayer boards (MLBs) contain many internal connections and heatconducting ground planes. This renders them as being very difficult to solder, and occasionally there may be an acceptable solder fillet on the soldering side, but only a limited appearance of solder on the component side. Such an example is shown in Figure 8. The void is now considered to be a minor defect that can be accepted during inspection. Extensive thermal cycling tests, and subsequent exposure to 
Figure 8 The terminal pad on the component side (a) and (b), shows solder flow-through, and a solder fillet between the lead and pad for greater than, "a minimum of $25 \%$ of the circumference". This is acceptable (ECSS-Q-70-08B, 2008)

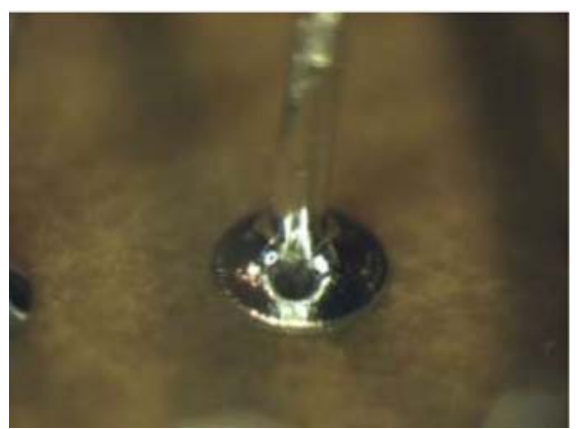

(a) Void in solder fillet on component-side of mlb

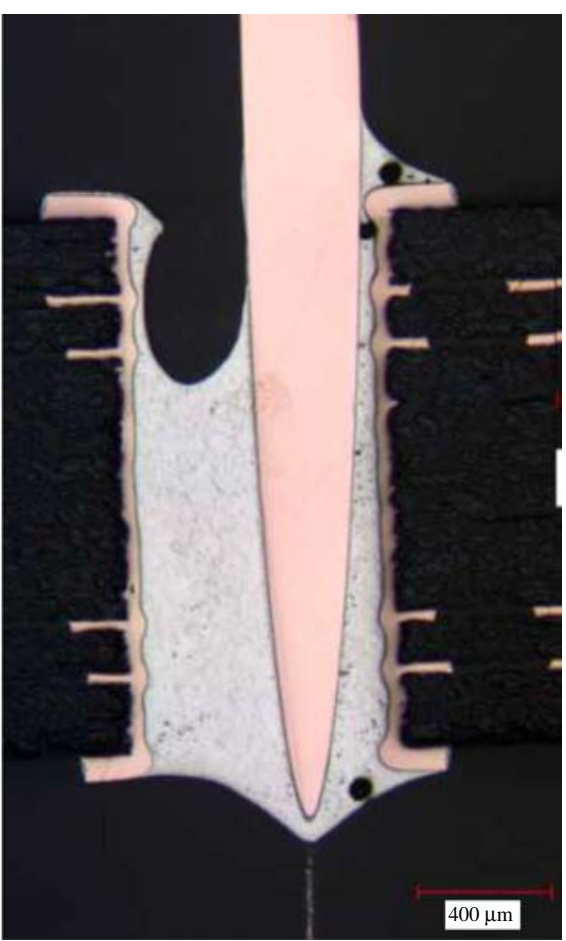

(b) Microsection through (a) showing good wetting angles of solder to lead and pad severe vibration testing, have proven this kind of minor defect to have no influence on the reliability of the joint.

Difficult-to-solder MLBs are sometimes reworked by trained operators. Testing at ESA has shown that boards procured to ESA standards can survive up to ten solder reworking operations before becoming damaged. However, occasionally defects are created. Figure 9 shows an electrically

Figure 9 Excessive rework can break the plated connection between internal copper and plated-through copper as was the case for this multilayer board (indium-lead sold onto gold-plated nickel finished MLB)

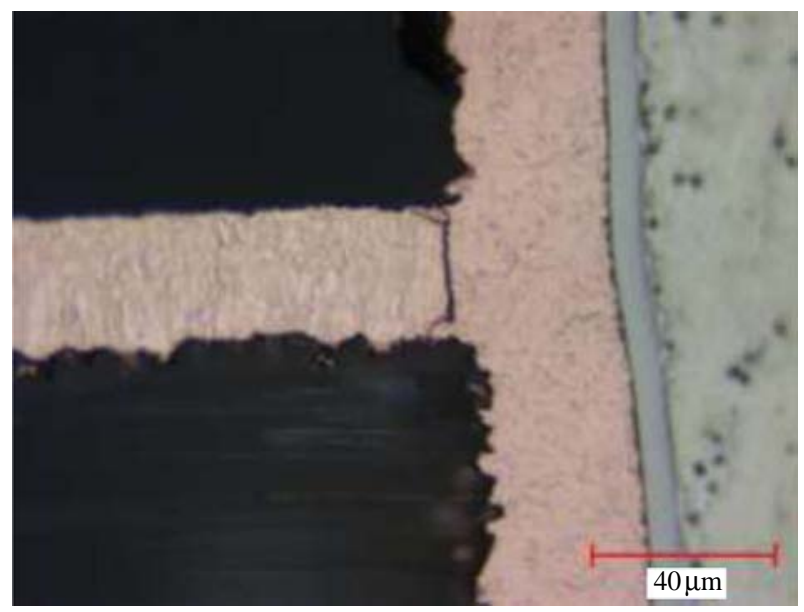

intermittent joint - operation at low temperatures causes the glass-epoxy laminate to contract more than the copper. The result is that the copper internal tracks are pulled away from the plated through copper to cause an open circuit which switches on as the temperature is again raised.

Operator certification is needed for standard repair activities on PCB assemblies, semi-rigid cable assembly, crimping, wire wrapping, and other processes which are covered by ECSS standards. Crimping and wire wrapping (now seldom selected) are also controlled by the metallographic examination of in-line samples. The microsections are then compared against defined accept/reject workmanship samples such as that shown in Figure 10.

Surface mount assembly processes are different in that they require a very precise "Verification programme" in order to achieve ESA-approval. Here it is the machine, rather than the operator which is assessed. The methodology for gaining SMT approval (i.e. approval per project by means of the declared processes list) is outlined in Annex 1 of ECSS-Q-7038A (2007). This involves:

- a written request for process verification;

- generation of a process identification document;

- manufacture of technology samples that need to conform to ECSS workmanship standards;

- an audit of the processing line;

- performing the verification programme consisting of subjecting samples (defined components, PCB material, staking and conformal coating, etc) to environmental testing; and 
Figure 10 Microsection through crimped joint shows good deformation of wire strands, less than 10 per cent voiding and no barrel cracking - acceptable workmanship

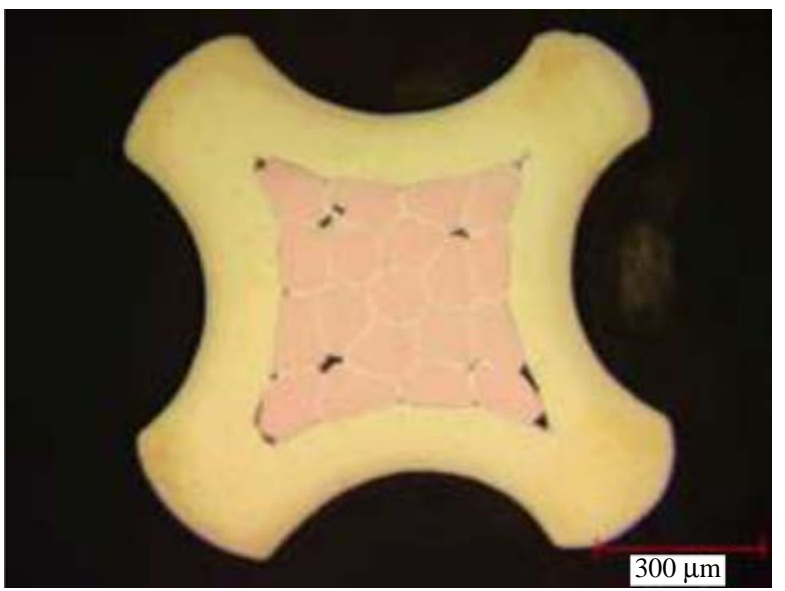

- visual, electrical and metallographic tests which define whether the soldered interconnection designs have passed or failed this programme. Clear workmanship accept/ reject criteria are included in the standard.

The verified SMT components are then listed on summary tables which identify all the variants of processing, PCB material, component dimensions and the like (see Annex B of the standard). Reference to these summary tables are made on the relevant ESA project's declared processes list ECSS-Q70B (2004) and ECSS-Q-70-38A (2007).

\section{ESA-approved skills training schools}

With the issue of the first European soldering workmanship standard in 1972 came the question of "training". The ESA Product Assurance manager at that time - David Nutt negotiated an agreement with his NASA counterparts, in order that five ESA staff could be trained and certified to instructor level in the domains of: hand soldering, crimping, semi-rigid cable assembly, machine soldering, conformal coating and module welding. This was done at TRW in Redondo Beach, Ca. Based on that experience, recommendations were made, and a concept was detailed for ESA training at a school within Europe (Titterton et al., 1973).

The first ESA-approved skills training school was set up at the German Welding Institute (SLV) close to Munich in 1979. Training then moved to ZVE's site in Oberfaffenhofen where courses were given in both English and German language. ESA now supports six schools situated in Germany, UK, France, Italy and Denmark. They cater for training in almost all the languages of ESA's Member States.

ESA's goals in supporting the skills training schools are to develop and maintain a pool of personnel trained in best practices for electronic assembly and improve the quality of electronic products used for spacecraft projects. Attendees to the schools' courses are able to gain certificates at operator (Category 3), inspector (Category 2) and instructor levels (Category 1). A summary of the training modules is given in Figure 11. Certificates are issued, based on the passing of both written and practical examinations. The Managers of each school are requested to attend an annual meeting which reviews changes to the ECSS standards, course material and revisions, technology advancements and the results of ESA studies. The course contents are harmonised and it is established that each school maintains a similar level of examination, using both the same questions template and the same printed circuit board and component kit for the assessment of practical skills. Attendance to the ESA skills training schools remains in the region of $700-800$ students per year. It is envisaged that a similar number of persons also attend courses that are delivered by Category 1 instructors, within the larger space companies, where they are employed.

\section{Coordination with NASA on workmanship issues}

An excellent relationship has always existed between ESA and NASA in the area of process standardization and workmanship. Not only have ESA staff and the ESA Schools instructors' gained certification at NASA training schools on the East and West coasts of the USA (respectively, at the Goddard Spaceflight Centre, and at the Jet Propulsion Laboratory), ESA has also been party to the review of each others workmanship standards. Importantly, ESA is a member of the NASA Workmanship Technical Committee, and have presented the results of the European studies (such as those in Zou et al. (1999), Adile et al. (1999), Wickham et al. (1999), Thomas and Dunn (1999), Tegehall and Dunn (2001a, b)(2005)(2006), Dunn and Tegehall (2003), ECSSQ-70-38A (2007) and Schonbeck and Dunn (2004) at past committee meetings.

During the International Space Station (ISS) programme, both ESA and NASA have performed an in-depth assessment of ESA documents (ESA-PSS specifications) and where they can be used in place of the NASA applicable documents. The bilateral safety and product assurance baseline for ISS contain a traceability matrix (NASA-Johnson Space Center, 1997). That document is an agreement that the NASA requirements for materials and processes (SSP-30233, rev. C) are equivalent to the ESA requirements for $\mathrm{M} \& \mathrm{P}$ as were specified in PSS-01-70 (which has now been updated in ECSS-Q-70B (2004)). It appears that no formal "meets or exceeds" exercise has been performed to equate NASA and ESA workmanship standards. However, owing to the crossfertilization of technical data and process requirements across the ocean, it is clear that the ESA and NASA standards listed in Table II have very similar requirements but, as is always the case, the differences are in the details.

In addition to the familiar standards shown in Table II, NASA has a well-developed conformal coating and staking standard (NAS 5300.4(3J-1)) - this is not a mandatory ESA process, but when used with SMT the materials and application process must be assessed as part of a Verification programme per ECSS-Q-70-38.

ESA is a member of the IPC, but unlike NASA, is not committed to utilising the Space Addendum 1 attached to IPC J-STD-001. Both NASA and ESA intend to issue workmanship standards for the manufacture of wire harnesses. 
Figure 11 Flow chart employed by ESA-approved skills training schools for the certification of operators, inspectors and instructors

ESA Training Structure

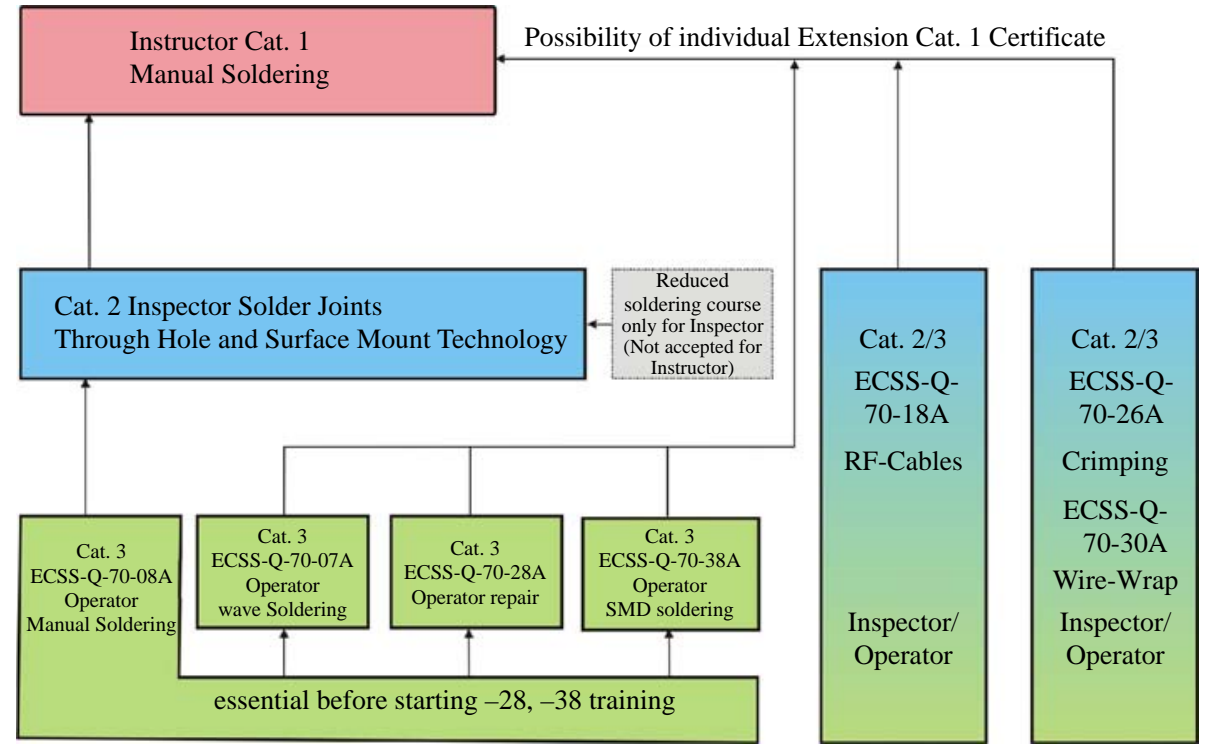

Table II Similarity between ESA and NASA workmanship standards

\begin{tabular}{|c|c|c|}
\hline Process Name & $\begin{array}{c}\text { ESA-ECSS } \\
\text { reference } \\
\text { number }\end{array}$ & $\begin{array}{c}\text { NASA-STD } \\
\text { reference } \\
\text { number }\end{array}$ \\
\hline Machine, wave soldering & Q-70-07 & Detail in 8739.3 \\
\hline Manual soldering & Q-70-08 & 8739.3 \\
\hline RF semi-rigid soldering coax cables & Q-70-18 & 8739.3 and 8739.4 \\
\hline Crimping & Q70-26 & 8739.4 \\
\hline Repair and modification & Q-70-28 & \\
\hline Wire wrapping & Q-70-30 & \\
\hline Surface-mount technology & Q-70-38 & 8739.2 \\
\hline Optical fibres & Q-70-51 & 8739.5 \\
\hline
\end{tabular}

\section{Conclusion}

Small studies, as reported in this paper, are essential in order to understand the chemistry and metallurgy of electrical interconnections.

A good understanding of the process is needed before any workmanship standards can be generated.

The training of operators and inspectors related to spacecraft assembly processes is important and their work needs to be continually reviewed.

Workmanship defects are often classified as major, minor, or cosmetic. Major defects could reduce the operational life of a space system and they need to be repaired (or reworked) using verified processes. Most minor and cosmetic defects do not warrant repair (or rework) and more harm than good often results from unnecessary rework.

I would finally like to re-iterate the sentiments of John Maristch who was once my Workmanship counterpart at NASA-GSFC. As our space projects become more global, we should be working more closely with out international partners: ESA, NASA, National Space Development Agency of Japan (NASDA), Centre National d'Etudes
Spatial (CNES), Canadian Space Agency (CSA), etc. This might reduce the disparity between these Agencies regarding workmanship requirements, suppliers' processes verification, and materials selection.

\section{Additional information}

Many of the publications referenced below can be seen on http:// esmat.esa.int and examples of further workmanship issues are related in Dunn (1997). This paper was presented at the Trilateral (ESA, NASA and JAXA (Japan Aerospace Exploration Agency)) Safety and Mission Assurance Conference held at ESA-Estec, Noordwijk, The Netherlands 14-16 April, 2008.

\section{References}

Adile, E., Picollo, P. and Dunn, B.D. (1999), "Effetto della geometria del raccordo di lega saldante sul comportamento a fatica meccanica di saldature di componenti elettronici a montaggio superficiale", Rivista Italiana Della Saldatura, Vol. 4, pp. 401-12.

Dunn, B.D. (1976), "Whisker formation on electronic materials", ESA Scientific and Technical Review, Vol. 2, pp. 1-10.

Dunn, B.D. (1978), "Producing reliable joints for spacecraft electronics", Electronic Production, April, pp. 23-30.

Dunn, B.D. (1987), A Laboratory Study of Tin Whisker Growth, ESA STR-223.

Dunn, B.D. (1988), "Mechanical and electrical characteristics of tin whiskers", ESA fournal, Vol. 11/12, pp. 1-17.

Dunn, B.D. (1997), Metallurgical Assessment of Spacecraft Parts, Materials and Processes, Praxis Publishing, Chichester.

Dunn, B.D. and Chandler, C. (1980), "The corrosive effect of soldering fluxes and handling in electronic materials", Welding Fournal, Vol. 59, pp. 289-307. 
Dunn, B.D. and Tegehall, P-E. (2003), Impact of Cracking Beneath Solder Pads in PCB Laminate on Reliability of Ceramic Ball Grid Array Packages, ESA STM-267 ESA, Paris.

ECSS-23500 (n.d.), Requirements for Lead Materials and Finishes for Components for Space Application.

ECSS-Q-60 (n.d.), EEE Components.

ECSS-Q-70-08B (2008), The Manual Soldering of High Reliability Electrical Connections.

ECSS-Q-70-38A (2007), High-reliability Soldering for Surface Mount and Mixed Technology, October.

ECSS-Q-70-71 (n.d.), Data for the Selection of Space Materials and Processes.

ECSS-Q-70B (2004), Materials, Mechanical Parts and Processes, December.

ESRO (1972), The Manual Soldering of High Reliability Electrical Connections, QRM-08, Issue 1.

NASA (n.d.), Requirements for Soldered Electrical Connections, NHB 5300-4.

NASA-Johnson Space Center (1997), International Space Station Program Baseline, SSP-50191, December 31.

Schonbeck, J. and Dunn, B.D. (2004), Evaluation of a Process for the Repair of Area Array and Other Surface Mounted Devices, ESA STM-272.

Tegehall, P-E. and Dunn, B.D. (2001a), Evaluation of Thermally Conductive Adhesives as Staking Compounds for Spacecraft Electronics, ESA STM-265.
Tegehall, P-E. and Dunn, B.D. (2001b), Assessment of the Reliability of Ball and Column Grid Array Packages for Space Applications, ESA STM-266, ESA, Paris.

Tegehall, P-E. and Dunn, B.D. (2005), Impact of Reworking Ceramic Area Grid Array Packages on the Integrity of Printed Board Laminate, ESA STM-273, ESA, Paris.

Tegehall, P-E. and Dunn, B.D. (2006), Evaluation of Cleanliness Test Methods for Spacecraft PCB Assemblies, ESA STM-275.

Thomas, G. and Dunn, B.D. (1999), "Assessment of ECAs for joining SMDs to pcbs", paper presented at Second International IEEE Symposium on Polymer Electronics Packaging, Gothenburg, Sweden, October, ESA, Paris.

Titterton, L. and Dunn, B.D. et al. (1973), "TRW Skills Training Report", ESA/EOQ/3574, October, ESA, Paris.

Wickham, M., Adams, D. and Dunn, B.D. (1999), An Investigation into Ball Grid Array Inspection Techniques, ESA STM-261, ESA, Paris.

Zou, L., Hunt, C. and Dunn, B.D. (1999), “An evaluation of the effect of ageing on the cleanability of solder flux residues", Soldering and Surface Mount Technology, Vol. 11, pp. 27-35.

\section{Corresponding author}

Barrie D. Dunn can be contacted at: barrie.dunn@esa.int

To purchase reprints of this article please e-mail: reprints@emeraldinsight.com Or visit our web site for further details: www.emeraldinsight.com/reprints 